\title{
The Effects of Unemployment and Insecure Jobs on Well-Being and Health: The Moderating Role of Labor Market Policies
}

\author{
Jonas Voßemer $^{1}$ (D) Michael Gebel $^{1} \cdot$ Kadri Täht $^{2}$ • \\ Marge Unt ${ }^{2} \cdot$ Björn Högberg ${ }^{3} \cdot$ Mattias Strandh $^{3}$
}

Accepted: 11 July 2017/Published online: 24 July 2017

(C) The Author(s) 2017. This article is an open access publication

\begin{abstract}
Labor market insecurities have been growing in Europe and previous research has illustrated that unemployment and insecure jobs negatively affect individuals' wellbeing and health. Although empirical evidence suggests that these effects vary substantially across different welfare states, we still know little about the moderating role of specific labor market policies. Taking a cross-national comparative perspective, this article investigates how passive and active labor market policies (PLMP, ALMP) as well as employment protection legislation (EPL) shape the experience of unemployment and insecure jobs. We complement micro data of round 1-6 (2002-2012) of the European Social Survey with time-varying macro indicators of PLMP, ALMP, and EPL. The data include about 89,000 individuals nested in 112 country-rounds and 26 countries respectively. We apply three-level random intercept models as well as pooled linear regression models including country fixed effects. The results show that labor market policies are important in shaping the experience of unemployment, but are less relevant for workers in insecure jobs. Specifically, higher unemployment benefit generosity buffers the negative effects of unemployment on well-being but not health. Moreover, we discuss different interpretations for the finding that higher ALMP expenditures are associated with more negative effects of unemployment on well-being and health. With respect to EPL it is found that in countries with high insider protection, deregulating the restrictions on the use of temporary employment increases the negative effects of unemployment on well-being and health.
\end{abstract}

Electronic supplementary material The online version of this article (doi:10.1007/s11205-017-1697-y) contains supplementary material, which is available to authorized users.

Jonas Voßemer

jonas.vossemer@uni-bamberg.de

1 Department of Sociology, University of Bamberg, Feldkirchenstraße 21, 96045 Bamberg, Germany

2 Institute of International Social Studies, Tallinn University, Uus-Sadama 5, 10120 Tallinn, Estonia

3 Department of Social Work, Umeå University, Samhällsvetarhuset, 90187 Umeå, Sweden 
Keywords Unemployment · Temporary employment · Fixed-term contract · Job insecurity · Well-being · Life satisfaction · Happiness · Health · Comparative · Crossnational $\cdot$ Multi-level $\cdot$ Labor market policies $\cdot$ Welfare state $\cdot$ Institutions

\section{Introduction}

Over the last three decades, the nature of work has strongly changed and labor market insecurities have been growing in many European countries (Scherer 2009; OECD 1997, 2002). Against this background, social scientists across different disciplines have examined the consequences of these changes for individuals' well-being and health. Specifically, research on the effects of unemployment on health (see Paul and Moser 2009; Wanberg 2012 for reviews and meta-analyses) has been complemented by studies on the consequences of temporary employment (see De Cuyper et al. 2008; Virtanen et al. 2005 for reviews and meta-analyses) and job insecurity (see De Witte 2005; Sverke et al. 2002 for reviews and meta-analyses) for workers' well-being.

Despite having learned a lot about why unemployment, and to a lesser extent insecure jobs, negatively affect individuals' well-being, we know little about factors that buffer or exacerbate these consequences. Only a small number of previous studies have taken a cross-national comparative perspective and addressed the moderating role of welfare state institutions such as passive and active labor market policies (PLMP, ALMP) as well as employment protection legislation (EPL). From a policy point of view, it seems, however, not only important to know that the negative effects of unemployment and insecure jobs vary across different welfare states (e.g., Bambra and Eikemo 2009; Kim et al. 2012), but also to identify which specific policies shape the experience of unemployment and insecure jobs.

Among the studies that have examined the moderating role of welfare state institutions, most have focused on PLMP that compensate for the income loss associated with unemployment (see O'Campo et al. 2015 for a review). With few exceptions (e.g., Eichhorn 2014), these studies suggest that the negative effect of unemployment is buffered by more generous unemployment benefits. Interestingly, this research does not, however, distinguish between workers in secure and insecure jobs, ignoring that PLMP may also reduce the negative effects of job insecurity by reducing the anticipated costs of future unemployment (e.g., Carr and Chung 2014; Scherer 2009). Bringing together the research on unemployment and job insecurity seems important, because it has been suggested that the growth of flexible employment has blurred the line between unemployment and employment. This not only raises the question whether insecure jobs have negative effects on well-being and health that are similar to those of unemployment, but also to what extent labor market policies, that have mostly been designed to tackle the latter, can shape the experience of insecure jobs, too.

Moreover, we extend previous research by taking into account two additional labor market policies. While unemployment benefits are arguably the most important policy, other welfare state institutions are expected to shape the experience of unemployment and job insecurity as well. Based on theories concerning why unemployment and insecure jobs negatively affect well-being and health (Nordenmark and Strandh 1999), ALMP and EPL are considered relevant. Training programs or job creation measures not only affect the employability of unemployed individuals, but also may provide a functional equivalent to employment (e.g., Carr and Chung 2014; Wulfgramm 2014). On the other hand, EPL affects both the (re-) employment chances of labor market outsiders (i.e., unemployed, 
workers in insecure jobs) as well as the relation between permanent and temporary employment. Where EPL for regular employment is low, differences by contract status may be less important. We also extend previous studies (e.g., Scherer 2009) by differentiating between EPL for regular employment and restrictions concerning the use of temporary employment. This is important as the literature on deregulation has repeatedly highlighted that many countries have reduced the latter, while leaving the protection for workers in regular employment unchanged (e.g., Barbieri 2009).

To summarize, we address the following research questions: First, what are the effects of unemployment and insecure jobs on well-being and health? Second, how do PLMP and ALMP as well as EPL moderate these effects?

We address these questions by using micro data from round 1-6 (2002-2012) of the European Social Survey (ESS). The ESS includes information on about 89,000 individuals nested in 112 country-rounds and 26 countries. The micro data are complemented by time-varying macro indicators on labor market policies. In contrast to previous studies, we distinguish between employees with permanent contracts and those who have fixed-term contracts or no contract at all to allow for a differentiated investigation of the moderating effects of different labor market policies. Analyzing self-rated health in addition to well-being also allows examining whether labor market policies are able to affect less malleable outcomes, too. Moreover, comparing the moderating role of PLMP, ALMP, and EPL within a single article, allows taking account of their interrelations. Methodologically, we estimate three-level random intercepts models to take account of the nesting of individuals in country-rounds and countries (Schmidt-Catran and Fairbrother 2016).

To examine the robustness of our results with respect to omitted variable bias at the country-level, we also make use of the fact that the ESS includes almost all countries repeatedly. Following two recent studies on the overall effect of different labor market policies on well-being (Boarini et al. 2013; Ochsen and Welsch 2012), we estimate pooled linear regression models with country and time fixed effects. These models only use within-country changes in labor market policies over time to identify the moderating effects of welfare state institutions on the well-being and health consequences of unemployment and insecure jobs. This not only reduces problems of spurious correlation at the country-level, but also has the advantage that cultural biases in subjective well-being or health reports are mostly ruled out (Boarini et al. 2013).

The remainder of this article proceeds as follows: the next section addresses the question why unemployment and insecure jobs should have negative effects on well-being and health and, specifically, how these negative effects may be moderated by different labor market policies. The following section presents the data, measures, and methods followed by a discussion of the results. The last section summarizes the findings and offers some concluding remarks.

\section{Theory and Hypotheses}

In the following, we outline a basic micro-macro model to derive hypotheses about the moderating role of labor market policies. At the micro-level (Sect. 2.1), the previous literature offers a great number of theoretical discussions about why unemployment and job insecurity should have negative effects on well-being and health. Because a complete review of these is beyond the scope of our article (see De Cuyper et al. 2008; De Witte 
2005; Ezzy 1993; Paul and Moser 2009; Strandh 2000; Sverke et al. 2002 for more detailed discussions), we rely on a synthesis by Nordenmark and Strandh (1999). Based on this, we explain in detail how different labor market policies are expected to either buffer or exacerbate the well-being and health consequences of unemployment and insecure jobs (macro-level, Sect. 2.2).

\subsection{Unemployment, Insecure Jobs, and Well-Being and Health}

Why should unemployment and insecure jobs negatively affect well-being and health? Based on previous theories, Nordenmark and Strandh (1999) highlight two rewards of employment that allow individuals to fulfill their socially defined needs: economic and psychosocial. In societies where employment is the norm and represents the main source of income, work is central to individuals' identity and participation in society. Accordingly, unemployment deprives individuals of these rewards and is therefore expected to negatively affect individuals' well-being.

Specifically, the income loss associated with unemployment not only requires individuals to adjust their standard of living, but also restricts the control over their own situation and ability to plan ahead (Strandh 2000). For example, the lack of economic resources is likely accompanied by increased stress, because individuals have to delay important decisions (e.g., family formation). Moreover, the need to find gainful re-employment may transfer into social problems like leaving behind family and friends when moving for a new job. Over time increased stress is also expected to accumulate into physical illness. Additionally, physical health may be affected by decreases in healthpromoting and increases in health-damaging behavior (Korpi 2001). Besides its financial consequences, job loss is also thought to deprive individuals of psychosocial benefits (e.g., Jahoda 1982). Jobs not only offer economic rewards, but also provide a major social role that defines individuals' social standing and identity. Accordingly, unemployed individuals are often stigmatized as non-useful, which likely has negative effects on their self-esteem and personal well-being.

Hypothesis 1 Compared with employment, unemployment has a negative effect on individuals' well-being and health.

The argumentation can also be adapted to explain why insecure jobs should negatively affect well-being and health (e.g., De Witte 2005). First, it is often argued that insecure jobs carry along a threat of unemployment meaning that workers perceive an increased risk to lose the economic and psychosocial rewards of employment. The mere uncertainty about whether one will be employed is also thought to have negative consequences for workers' well-being. Second, resolving the distinction between employment and unemployment emphasizes that insecure and secure jobs are likely associated with different amounts of economic and psychosocial rewards. For example, compared with permanent jobs, temporary jobs or jobs without any contract at all are by definition accompanied by less predictability and controllability (De Witte 2005). This restriction on individuals' ability to control their own situation and plan ahead is also reinforced by the lower remuneration of insecure jobs (Scherer 2009). Moreover, temporary employment is often considered as part of the labor market periphery, meaning that employers are unlikely to invest in these employment relationships, for example, in the form of continued training or opportunities for advancement (De Cuyper et al. 2008). In addition, insecure jobs have been shown to be associated with less pleasant working conditions 
(e.g., support, working hours) negatively affecting workers' well-being and health (De Cuyper et al. 2008; Scherer 2009).

Hypothesis 2 Compared with secure jobs, insecure jobs have a negative effect on wellbeing and health.

\subsection{The Moderating Role of Labor Market Policies}

How are these negative effects moderated by labor market policies? Following the previous literature (see O'Campo et al. 2015 for a review), it is reasonable to assume that the design of unemployment benefits moderates the effects of both unemployment and insecure jobs on well-being and health. It can be expected that the link between unemployment and health is weaker in countries that provide generous unemployment benefits in terms of coverage or eligibility, duration, and wage replacement. In these countries, most unemployed individuals receive benefits that compensate for the income loss for a comparatively long duration. Therefore, the unemployed are able to afford a search for adequate reemployment meaning that they do not have to fear any lasting negative career consequences. It is sometimes argued that higher generosity may exacerbate the negative effects by lengthening the unemployment duration. However, longer durations due to higher generosity may rather express choices and, thus, are unlikely to negatively affect wellbeing.

Besides counteracting the loss of economic rewards and preserving individuals' agency, generous unemployment benefits may also reduce the stigma attached to unemployment (e.g., Wulfgramm 2014). Moreover, unemployment benefits not only buffer the negative effects of job loss, but also provide a kind of "collective resource" to the currently employed (Sjöberg 2010: 1282). Specifically, the well-being of workers in insecure jobs should improve knowing that they will receive benefits that more or less preserve their standard of living. In other words, the threat of unemployment that accompanies insecure jobs becomes less important given that the experience of unemployment is expected to be less severe (Scherer 2009).

Hypothesis 3 The more generous the unemployment benefits, the weaker the negative effect of unemployment on well-being and health.

Hypothesis 4 The more generous the unemployment benefits, the weaker the negative effect of insecure jobs on well-being and health.

Few studies have moved beyond the moderating role of PLMP (see Wulfgramm 2014 for an exception). However, similar to unemployment benefits, ALMP are likely to shape the experience of unemployment and insecure jobs. With respect to the highlighted microlevel mechanisms, ALMP may improve unemployed individuals' well-being and health in two ways. First, training programs or job creation measures may offer a "functional equivalent" to employment, providing, for example, "social contacts, ... a clear time structure and ... the feeling of participating in a useful collective purpose" (Wulfgramm 2014: 261). Participating in these schemes should also equip the unemployed with a feeling of control counteracting the restrictions on individuals' agency. Second, in addition to providing some of the social rewards of employment, ALMP counteract the loss of human capital and improve unemployed individuals' chances for quick and adequate re-employment. In return, higher perceived employability should have a positive effect on wellbeing. However, if ALMP are also associated with lock-in effects, meaning that 
participants have no time for job search due to their program participation, the effects on re-employment chances may also be negative.

Similar arguments apply to workers in insecure jobs experiencing an ongoing threat of job loss. Specifically, ALMP should reduce insecure workers' fears about not being able to find adequate re-employment after becoming unemployed. To the extent that insecure workers perceive such measures as effective (Carr and Chung 2014), ALMP should decrease the negative effects of insecure compared with secure employment.

However, it has to be considered that the positive effects of training programs or job creation measures are dependent on how closely they resemble regular employment, how well they match participants' needs, and how they are perceived. For example, Strandh (2001) compared three measures including activation, vocational training, and workplace participation. Only involvement in workplace participation showed the assumed positive effects on well-being. Similarly, Gundert and Hohendanner (2015) show that the social integration effects of One-Euro-Jobs, a last resort programme administered to recipients of means-tested benefits in Germany, depend on participants' own perceptions. It only improves social integration for those unemployed who perceive participation as voluntary and beneficial. Related to this, it has been highlighted that not all ALMP are alike and that measures that have an enforcing character and are perceived as paternalistic may not improve unemployed persons' health (e.g., Wulfgramm 2014). Nevertheless, weighing the different arguments we derive the following hypotheses.

Hypothesis 5 The more support through active labor market policies, the weaker the negative effect of unemployment on well-being and health.

Hypothesis 6 The more support through active labor market policies, the weaker the negative effect of insecure jobs on well-being and health.

So far, almost no studies have examined the moderating role of EPL (see Scherer 2009 and Ochsen and Welsch 2012 for exceptions) and the few available studies do not distinguish between the protection of regular employment and restrictions on the use of temporary employment. ${ }^{1}$ However, it can be assumed that regulations governing the hiring and firing of workers are important for how unemployment and insecure jobs are perceived and, thus, affect well-being and health.

Specifically, economic theory argues that strict EPL for regular employment increases the costs of firing and hiring workers and, therefore, reduces transitions into and out of unemployment (Ochsen and Welsch 2012). Accordingly, the resulting longer unemployment duration should be associated with more negative effects on well-being and health. First, longer durations should increase financial insecurities, because, in most countries, unemployment insurance benefits are replaced by unemployment assistance over time. Moreover, personal and household savings will exhaust the longer the unemployment spell lasts. Second, longer durations are also associated with greater stigma and lower chances of finding adequate re-employment. Similar arguments apply with respect to insecure jobs. Strict EPL for regular employment reinforces the distinction between labor market insiders (workers with permanent contracts) and outsiders (temporary contract, no contract) (Scherer 2009). Consequently, it can be expected that conversion rates from temporary to regular employment are lower in these countries. Anticipating that it will be difficult to find re-employment

\footnotetext{
${ }^{1}$ Boarini et al. (2013) examine the overall effects of EPL on well-being. They are, however, not able to differentiate between employed and unemployed individuals or between workers with different contract statuses.
} 
after job loss, the negative effect of insecure jobs on well-being is likely exacerbated. Furthermore, strict EPL for regular employment should improve secure' workers well-being and, therefore, in addition, contribute to greater inequalities by contract status.

Hypothesis 7 The stronger the employment protection legislation for regular employment, the stronger the negative effect of unemployment on well-being and health.

Hypothesis 8 The stronger the employment protection legislation for regular employment, the stronger the negative effect of insecure jobs on well-being and health.

It is also reasonable to assume that in countries with strict EPL for regular employment deregulating the use of temporary contracts exacerbates the negative effects of unemployment and insecure jobs. In this case of a partial or target deregulation (Barbieri 2009), becoming unemployed may not only be associated with longer unemployment durations, but also with the risk of finding only temporary re-employment followed by cycles of nonemployment and temporary jobs. For workers in insecure jobs, the perceived negative consequences of job loss increase accordingly. In other words, a so-called flexibilization at the margins is assumed to result in a particularly strong cleavage between insiders and outsiders.

Hypothesis 9 In countries with strong employment protection legislation for regular employment, reducing the restrictions on the use of temporary employment, results in a stronger negative effect of unemployment on well-being and health.

Hypothesis 10 In countries with strong employment protection legislation for regular employment, reducing the restrictions on the use of temporary employment, results in a stronger negative effect of insecure jobs on well-being and health.

\section{Data and Methods}

\subsection{Micro Data}

We draw on comparative micro data of round 1-6 (2002-2012) of the European Social Survey (ESS). ${ }^{2}$ The data are collected every two years and the majority of the 36 countries participate repeatedly. The number of countries per round ranges from 22 in 2002 and 2014 to 31 in 2008. The data are based on random probability samples in each country and round. The respective population of interest is all persons aged 15 and over residing within private households (European Social Survey 2016: 7). We chose the ESS for three reasons. First, compared with other international surveys, it is of very high quality (e.g., Kohler 2008; in 2005 the ESS won the Descartes Price of the European Union for its advancements in survey research). Second, it is the only European survey that offers detailed information on well-being, health, and employment status while simultaneously including many countries repeatedly. This allows us to not only compare the effects of unemployment and insecure jobs across countries, but also to examine changes within countries over time. Third, some previous studies on the moderating role of labor market policies have used the ESS (e.g., Carr and Chung 2014; Scherer 2009; Wulfgramm 2014) allowing us to interpret our findings in the context of their results.

${ }^{2}$ We use the following integrated data files: ESS Round 1: Edition 6.4, ESS Round 2: Edition 3.4, ESS Round 3: Edition 3.5, ESS Round 4: Edition 4.3, ESS Round 5: Edition 3.2, ESS Round 6: Edition 2.2. 
For our analyses, data from round 1-6 (2002-2012) are pooled and the sample is restricted to employees and unemployed individuals aged 15-64 years. ${ }^{3}$ Unfortunately, the data do not allow identifying ALMP participants separately. In the results and conclusions section, we discuss how this issue affects the interpretation of the findings about the moderating role of ALMP. We focus on the 112 country-rounds from the 26 countries for which we have complete micro and macro data providing us with information about 89,000 individuals. The selection of countries and country-rounds is motivated by the principle of using as much information as possible. Supplementary material S1 describes in detail which country-rounds are used for the analyses and why certain country-rounds have been excluded. The average number of individuals per country-round is 797, ranging from 386 in Italy in 2012 to 1293 in Germany in 2010. Supplementary material S2 provides the number of individuals for each country and round. ${ }^{4}$

\subsection{Micro-level Variables}

Table 1 provides an overview on the measurement of the micro- and macro-level variables and Table 2 offers descriptive statistics on all micro-level variables. The key independent variable of interest is employment status. We use respondents' self-defined status to differentiate between individuals who are employed and unemployed. Among the former, we distinguish between workers in secure jobs having a contract of unlimited duration and workers in insecure jobs. The latter are comprised of employees with a fixed-term contract or no contract at all. Unfortunately, the data do not allow examining both groups separately, but based on our theoretical arguments, employees who have no contract at all are assumed to experience similar job insecurity as temporary workers.

The dependent variables well-being and health are based on self-reports. Specifically, subjective well-being is measured using the following question "All things considered, how satisfied are you with your life as a whole nowadays?" with answers on an 11-point scale ranging from 0 "extremely dissatisfied" to 10 "extremely satisfied". Global life satisfaction scales have been shown to be valid, reliable, and sensitive to change such that they are well-suited for our analyses (Diener et al. 2013). Specifically, they capture the socalled cognitive component of individuals' subjective well-being, that is, people's judgments about their life as a whole (Boarini et al. 2013). Moreover, Headey et al. (1993) suggest that life satisfaction also represents an important dimension of mental health.

Self-rated health is measured by the question "How is your health in general?" with answers ranging from 1 "very good" to 5 "very bad". Research has repeatedly shown that it is an independent predictor of mortality even after adjusting for a number of specific health measures and other covariates known to be relevant (e.g., Idler and Benyamini 1997). For the analyses, the responses are grouped into a binary variable $(1=$ "very good", "good"; 0 = "fair", "bad", "very bad"). Supplementary material S2 presents the average well-being and health for each country and round.

The analyses also control for variables that may confound the associations of unemployment and insecure jobs with well-being and health. These variables were chosen

\footnotetext{
${ }^{3}$ We excluded self-employed individuals, because the questions about contract status do not apply. Moreover, the theoretical arguments with respect to the moderating role of labor market policies (e.g., unemployment insurance benefits, employment protection legislation) are mostly concerned with employees. For similar reasons, we also excluded family workers.

4 We cannot use round 7 (2014) of the ESS, because for this year we often have no data on our indicators for unemployment benefit generosity and employment protection legislation. For round 6 (2012), we used macro data from 2011 for some indicators allowing us to include 15 additional country-rounds.
} 
Table 1 Measurement of the micro- and macro-level variables. Sources: Own illustration

\begin{tabular}{|c|c|}
\hline Variable & Measurement \\
\hline \multicolumn{2}{|l|}{ Micro-level variables } \\
\hline \multicolumn{2}{|l|}{ Dependent variables } \\
\hline Well-being & $\begin{array}{l}\text { Life satisfaction scale, Range: } 0=\text { extremely dissatisfied - } \\
10=\text { extremely satisfied }\end{array}$ \\
\hline Health & Self-rated health, $1=$ Very good, good; $0=$ fair, bad, very bad \\
\hline \multicolumn{2}{|l|}{ Independent variables } \\
\hline Employment status & $\begin{array}{l}3 \text { categories: } 1=\text { secure job (permanent contract), } 2=\text { insecure job (fixed- } \\
\text { term contract, no contract), } 3=\text { unemployed }\end{array}$ \\
\hline Sex & $1=$ female, $0=$ male \\
\hline Migration background ${ }^{a}$ & $\begin{array}{l}1=\text { migration background, } 0=\text { no migration background; based on } \\
\text { respondent's and parents' place of birth }\end{array}$ \\
\hline Age & In years \\
\hline Education & Completed full-time education in years \\
\hline Past unemployment & $\begin{array}{l}3 \text { categories: } 1=\text { Never unemployed }(>3 \text { months }), 2=\text { Unemployed }(>3 \\
\text { to }<12 \text { months), } \\
3=\text { Unemployed }(\geq 12 \text { months })\end{array}$ \\
\hline Father's education & $\begin{array}{l}3 \text { categories according to ISCED: } 1=\text { ISCED } 0-1,2=\text { ISCED } 2 \text {, } \\
3=\text { ISCED } 3,4=\text { ISCED } 4-6\end{array}$ \\
\hline Mother's education & $\begin{array}{l}3 \text { categories according to ISCED: } 1=\text { ISCED } 0-1,2=\text { ISCED } 2 \text {, } \\
3=\text { ISCED } 3,4=\text { ISCED } 4-6\end{array}$ \\
\hline \multicolumn{2}{|l|}{ Macro-level variables ${ }^{\mathrm{b}}$} \\
\hline Unemployment rate & Unemployment rate in percent \\
\hline Benefit generosity & $\begin{array}{l}\text { Index }=\text { average net replacement rate } \times \text { benefit duration in percent of } \\
48 \text { months, range: } 0=\text { no benefits }-100=\text { full replacement for } \\
48 \text { months or longer }\end{array}$ \\
\hline $\begin{array}{l}\text { Passive labor market } \\
\text { policies (PLMP) }\end{array}$ & Expenditure per unemployed as percent of GDP per capita \\
\hline $\begin{array}{l}\text { Active labor market policies } \\
\text { (ALMP) }\end{array}$ & Expenditure per unemployed as percent of GDP per capita \\
\hline $\begin{array}{l}\text { Employment protection } \\
\text { legislation (EPL) }\end{array}$ & $\begin{array}{l}\text { OECD EPL indicators for regular and temporary employment (version } 1 \text { ), } \\
\text { range: } 0=\text { unregulated }-6=\text { highly regulated }\end{array}$ \\
\hline
\end{tabular}

a Person is considered to have a migration background if born abroad or if born in country and both parents were born abroad, ${ }^{b}$ References to the macro data are given in supplementary material S3

assuming that they affect both workers' risk to experience unemployment or insecure jobs as well as their well-being and health. Besides socio-demographics such as sex, migration background, and age, we control for individuals' years of education, past unemployment experiences, and their social origin.

Migration background is a binary measure based on three questions about the respondents' and parents' country of birth. Individuals are considered to have a migration background if they were born abroad or if they were born in the country, but both parents were born abroad. Previous research also has shown that past unemployment may increase the risk of future unemployment or insecure jobs as well as have medium- to long-term negative effects on individuals' health (e.g., Strandh et al. 2014). Not controlling for past unemployment, therefore, likely results in an overestimation of the negative effects of current unemployment and insecure jobs. Specifically, we distinguish between workers 
Table 2 Descriptive statistics on the micro-level variables. Sources: European Social Survey, round 1-6 (2002-2012), 26 countries, 112 country-rounds. Own calculations

Table 1 provides details about the measurement

\begin{tabular}{lcc}
\hline & Mean/Percent & SD \\
\hline Dependent variables & & \\
Well-being & 6.98 & 2.16 \\
Health & 0.77 & \\
Independent variable & & \\
Employment status & & \\
$\quad$ Secure job & 0.73 & \\
Insecure job & 0.15 & \\
Unemployed & 0.12 \\
Control variables & & \\
Female & 0.49 \\
Migration background & 0.11 \\
Age & 40.94 \\
Years of education & 13.41 \\
Past unemployment & & \\
Never unemployed (>3 months) & 0.65 \\
Unemployed (>3 to <12 months) & 0.20 \\
Unemployed ( $\geq 12$ months) & 0.15 \\
Father's highest level of education & \\
ISCED 0-1 & 0.28 \\
ISCED 2 & 0.21 & \\
ISCED 3 & 0.33 \\
ISCED 4-6 & 0.18 \\
Mother's highest level of education & & \\
ISCED 0-1 & 0.30 & \\
ISCED 2 & 0.28 \\
ISCED 3 & 0.29 \\
ISCED 4-6 & 0.13 & \\
\hline
\end{tabular}

who have never been unemployed for more than three months and those who have either experienced short-term unemployment (between 3 and 12 months) or long-term unemployment (12 months or more) in the past. Social origin is measured by the educational qualifications of the parents using the International Standard Classification of Education (ISCED) and distinguishing between four groups respectively (ISCED 0-1, 2, 3, 4-6).

We do not control for variables such as living with a partner, being married, or having children. Although these variables are often included in related research, they may be regarded as consequences of unemployment or insecure jobs such that holding these factors constant is likely to result in over control bias.

\subsection{Macro-level Variables}

We complement the ESS with time-varying indicators about unemployment rates, unemployment benefit generosity, expenditures on PLMP and ALMP as well as EPL. References to these data are given in supplementary material S3. Table 3 provides descriptive statistics on the macro-level variables for each of the 26 countries. 


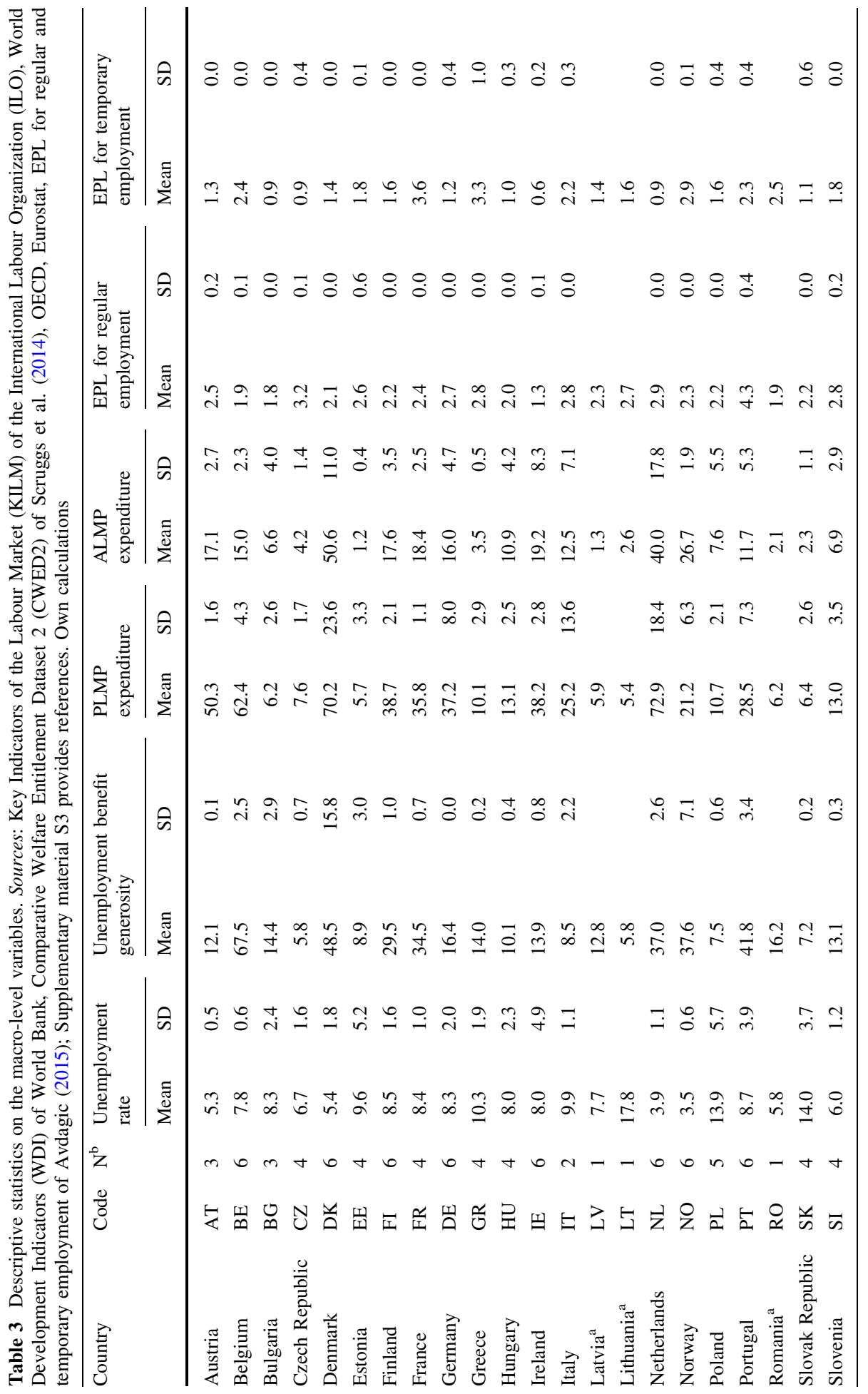




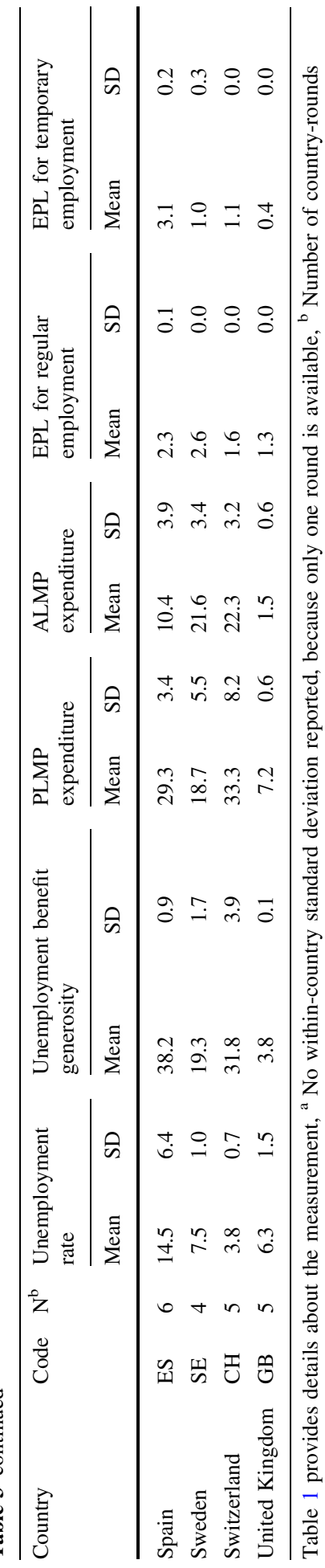


Because previous research has shown that the effects of unemployment and insecure employment may vary with countries' economic situation (e.g., Buffel et al. 2015; Scherer 2009), the analyses will include the harmonized unemployment rate taken from the Key Indicators of the Labour Market (KILM) of the International Labour Organization (ILO). Specifically, two different ways have been suggested in which the unemployment rate may moderate the experience of unemployment and insecure jobs (e.g., Oesch and Lipps 2013). First, high aggregate unemployment may increase the negative effects of unemployment and insecure jobs, because of the poor prospects for re-employment. Second, the negative effects of unemployment may be buffered for unemployed individuals during poor macroeconomic conditions, because unemployment can be attributed to external reasons. For workers in insecure jobs, higher unemployment rates may also buffer the negative effects as they may be happy to have a job at all, especially in a situation where there is a concrete threat of unemployment (Scherer 2009).

Information on unemployment benefit generosity is taken from the Comparative Welfare Entitlement Data 2 (CWED 2) by Scruggs et al. (2014). These include information about net replacement rates and unemployment benefit duration in weeks. ${ }^{5}$ The latter are re-expressed in percent of 48 months meaning that countries that offer unlimited duration or a duration of 48 months or more have a value of 100 . To measure benefit generosity we follow Wulfgramm (2014) and construct an index that multiplies the average of the net replacement rates for two household types (i.e., single and family) with the benefit duration in percent of 48 months. This index takes values between 0 and 100 .

Another measure of decommodification that has been used (Eichhorn 2014; Wulfgramm 2014 ) is the expenditure on PLMP including out-of-work income maintenance and support. Specifically, we measure how much a country spends on PLMP per unemployed as a percentage of GDP per capita. This measure is used for a robustness check. It not only covers unemployment insurance, but also unemployment assistance. However, compared with the benefit generosity index, it is less clear what aspects of decommodification are captured by it.

Similarly, to assess how much support the unemployed receive through ALMP, we consider the expenditure on ALMP per unemployed as a percentage of GDP per capita. The latter includes, for example, expenditure on training, employment incentives, and job creation (Eurostat 2013: 13-23). Expenditure data are taken from OECD and Eurostat. These measures are standardized by the number of unemployed and the GDP per capita to make sure that they are not mere reflections of countries' macro-economic conditions and take account of different levels of welfare across countries.

Information on EPL is taken from OECD (Venn 2009). For a few Central and Eastern European (CEE) countries, the OECD indicators have been complemented by information from Avdagic (2015) who scored CEE countries following the OECD approach. For the analyses, we focus on version 1 of the EPL indicators for regular and temporary employment. The indicator for regular employment is constructed from a number of items that capture different aspects of job security provisions (e.g., severance pay, advance notification) and varies between 0 (unregulated) and 6 (regulated). The indicator for temporary employment is based on items that reflect the types of work for which these contracts are allowed as well as their duration (e.g., maximum number of successive fixedterm contracts, number of renewals of temporary work agency assignments) and also varies between 0 (unregulated) and 6 (regulated).

\footnotetext{
5 For the calculation of the replacement rates an average production worker who is 40 years old and has been working 20 years before unemployment is assumed.
} 


\subsection{Methods}

To test our hypotheses we estimate two kinds of models. The first are linear randomintercept models with three levels. Following the recommendations of a recent simulation study on how to model random effects in "comparative longitudinal data" (Schmidt-Catran and Fairbrother 2016: 23), we assume that individuals $i$ are nested within country-rounds $t$ and countries $c{ }^{6}$ The model can be written as follows

$$
y_{c t i}=\beta_{0}+\beta_{t}+\sum_{p=1}^{P} \beta_{p} X_{p c t i}+\sum_{q=1}^{Q} \beta_{q} Z_{q c t}+\sum_{p=1}^{P} \sum_{q=1}^{Q} \beta_{p q} X_{p c t i} Z_{q c t}+v_{c}+u_{c t}+e_{c t i}
$$

where $y_{c t i}$ reflects an individual $i$ 's well-being or health in country-round $t$ and country $c$. The fixed part of the model includes the following terms: a grand average $\beta_{0}$, round fixed effects $\beta_{t}$, in order to capture common unobserved time-varying variables (e.g., common economic shocks), $P$ individual-level variables $X_{p c t i}$, such as employment status, and $Q$ time-varying country-level variables $Z_{q c t}$, including the different labor market policies. In addition, it includes cross-level interactions $X_{p c t i} Z_{q c t}$ to assess how the effects of individual-level variables, like employment status, are moderated by the time-varying labor market policies indicators. The random part consist of the three error terms $v_{c}$ (countrylevel), $u_{c t}$ (country-round-level), and $e_{c t i}$ (individual-level).

The second kinds are pooled linear regression models that include country fixed effects in addition to round fixed effects. To take account of the nesting structure, standard errors have been clustered at the country-level. Including country dummies results in a model that only uses the within-country variation in labor market policies over time to estimate their moderating effects. We, thereby, reduce problems concerning omitted variables bias at the country-level. For example, if stable social policy traditions affect both the arrangement of different labor market policies as well as the well-being consequences of unemployment and insecure jobs, estimates for the effects of labor market policies may be biased. Moreover, concerns about the cross-national comparability of subjective measures of wellbeing and health are reduced, as comparisons are made within countries over time (e.g., Boarini et al. 2013).

Note that we use linear models for both outcomes, the ordinal measure of well-being and the binary indicator of self-rated health. Following the previous literature (e.g., Eichhorn 2014; Wulfgramm 2014), we treat the 11-point life satisfaction scale as a cardinal measure of subjective well-being. Ferrer-i-Carbonell and Frijters (2004) suggest that assuming cardinality or ordinality makes little practical difference and the results of the linear models are readily interpretable. For our binary health measure, we estimate linear probability models instead of logistic or probit regression models, because the coefficients can be interpreted on the probability scale. Especially for the interpretation of interaction effects, linear models imply, in contrast to non-linear regressions, a straightforward interpretation.

To increase the interpretability of our results the macro-level variables have been centered and standardized to unit variance. Similarly, the continuous micro-level variables

\footnotetext{
${ }^{6}$ Actually, Schmidt-Catran and Fairbrother (2016) recommend a model where country-rounds are crossclassified within countries and rounds, and individuals are nested in country-rounds (Model F in their text). This model includes random effects at the country-, round-, and country-round-level. However, they also state that round-level random effects can be omitted if no round-level fixed effects are included in the model (p. 26, Model D in their text). Moreover, if round fixed effects are included, as in our specification, model D and $\mathrm{F}$ are the same.
} 
age and years of education have been centered and squared terms have been added to the models to allow for non-linear effects on well-being and health.

\section{Results}

\subsection{Well-Being}

Table 4 reports the results of a series of linear random intercept models. The intra class coefficient of the empty model (not shown) indicates that about 19 percent of the variance in life satisfaction is observed at the country and country-round level. This suggests that well-being varies substantially across welfare states. In line with hypothesis 1 as well as previous studies (Wulfgramm 2014), we find that unemployed individuals have, on average, about a one scale point lower life satisfaction compared with workers in secure jobs (model 1). This estimate is already adjusted for all individual-level control variables as well as round fixed effects. ${ }^{7}$ For workers in insecure jobs, the negative effect is smaller, but still practically and statistically significant. Workers who have a temporary contract or no contract at all, on average, have a 0.2 scale point lower well-being compared to those with permanent contracts (model 1). This confirms hypothesis 2 and is also consistent with previous findings (e.g., Scherer 2009). Overall, the effect of unemployment is five times larger than the effect of insecure jobs, suggesting that being employed is particularly important for individuals' well-being.

Models 2-4 test our hypotheses about the moderating role of PLMP, ALMP, and EPL. The positive cross-level interaction of being unemployed with benefit generosity suggests that higher unemployment benefits buffer the negative effect of unemployment on wellbeing (model 2). A one standard deviation increase in benefit generosity is predicted to reduce the negative effect by about 0.16 scale points. In contrast, for insecure jobs the interaction coefficient is small and not statistically significant. Figure 1 illustrates these findings by plotting the respective average marginal effects with $90 \%$ confidence intervals (y-axis) against the standardized benefit generosity indicator (x-axis).

The flat line for insecure jobs shows that higher unemployment benefits do not alleviate the negative effect of having a temporary contract or no contract at all. In contrast, for the same person becoming unemployed in a country with a benefit generosity of one standard deviation below the mean, as compared to a country with one standard deviation above the mean, makes a difference of about 0.3 scale points in the negative effect on well-being. Given an average effect of about one scale point this equals a $30 \%$ reduction. Thus, while hypothesis 3 can be confirmed, hypothesis 4 has to be rejected.

For ALMP we find no moderating effect on the effect of having an insecure job on wellbeing (hypothesis 6). However, model 2 suggests that higher spending on ALMP is associated with a more negative effect of unemployment. Specifically, a one standard deviation increase in ALMP is predicted to increase the negative effect on well-being by about 0.17 scale points. Assuming that ALMP participants are mostly included among the unemployed, this finding contradicts hypothesis 5 and suggests that higher ALMP expenditure exacerbates the negative effect of unemployment. However, if one assumes that ALMP participants are mostly included with the employed, the same finding may be interpreted more positively. In this case, in countries or country-rounds with higher ALMP

\footnotetext{
${ }^{7}$ We focus on the coefficients of interest in Tables 4, 5, 6 and 7. Tables including the full results are available in supplementary material $\mathrm{S} 4$.
} 
Table 4 Linear random intercept models (dependent variable: well-being, scale points). Sources: European Social Survey, round 1-6 (2002-2012); Tables 1 and 3 provide details about the macro data. Own calculations

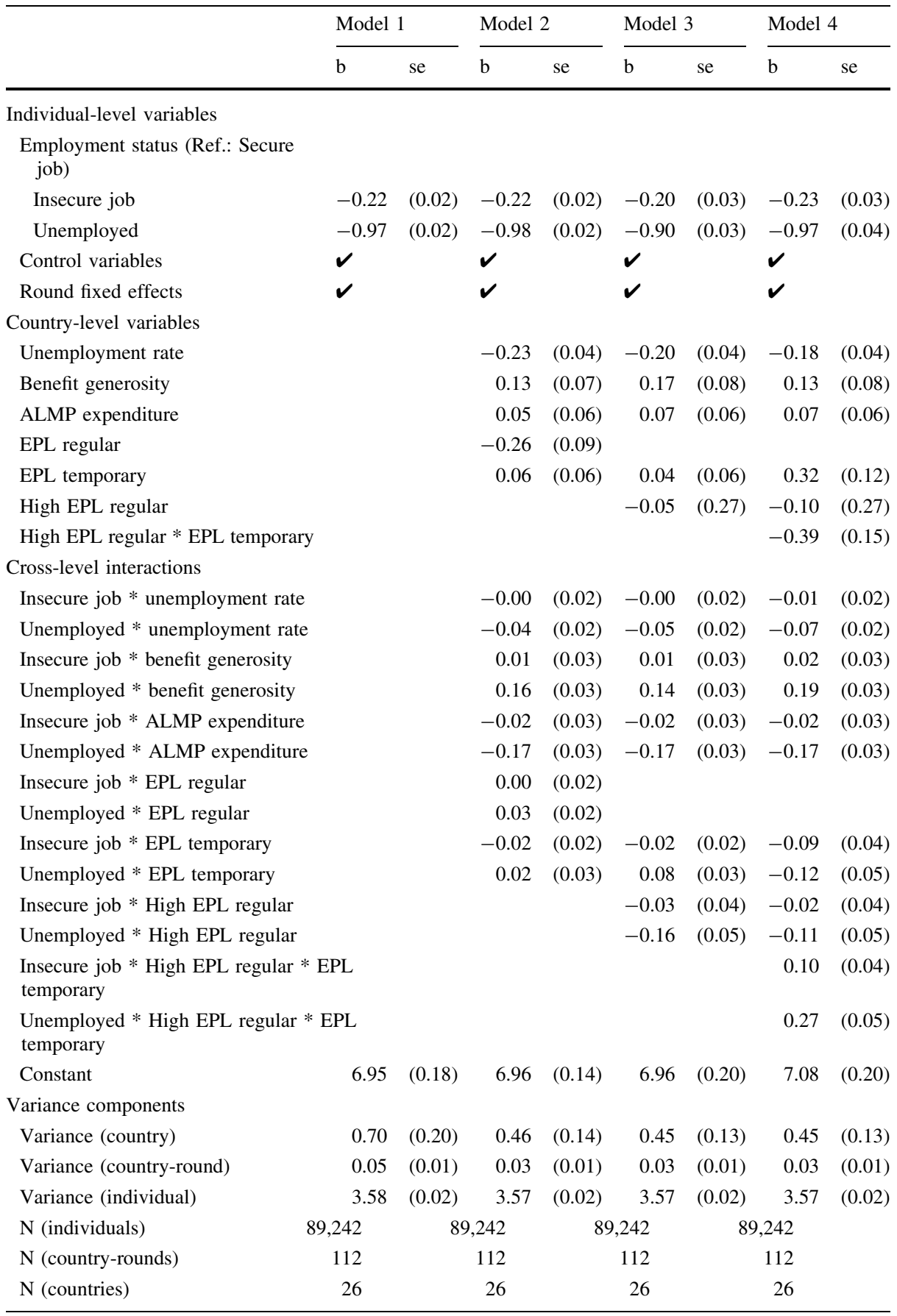

See Table 1 for a list of the individual-level control variables 
Table 5 Pooled linear regression models (Dependent variable: well-being, scale points). Sources: European Social Survey, round 1-6 (2002-2012); Tables 1 and 3 provide details about the macro data. Own calculations

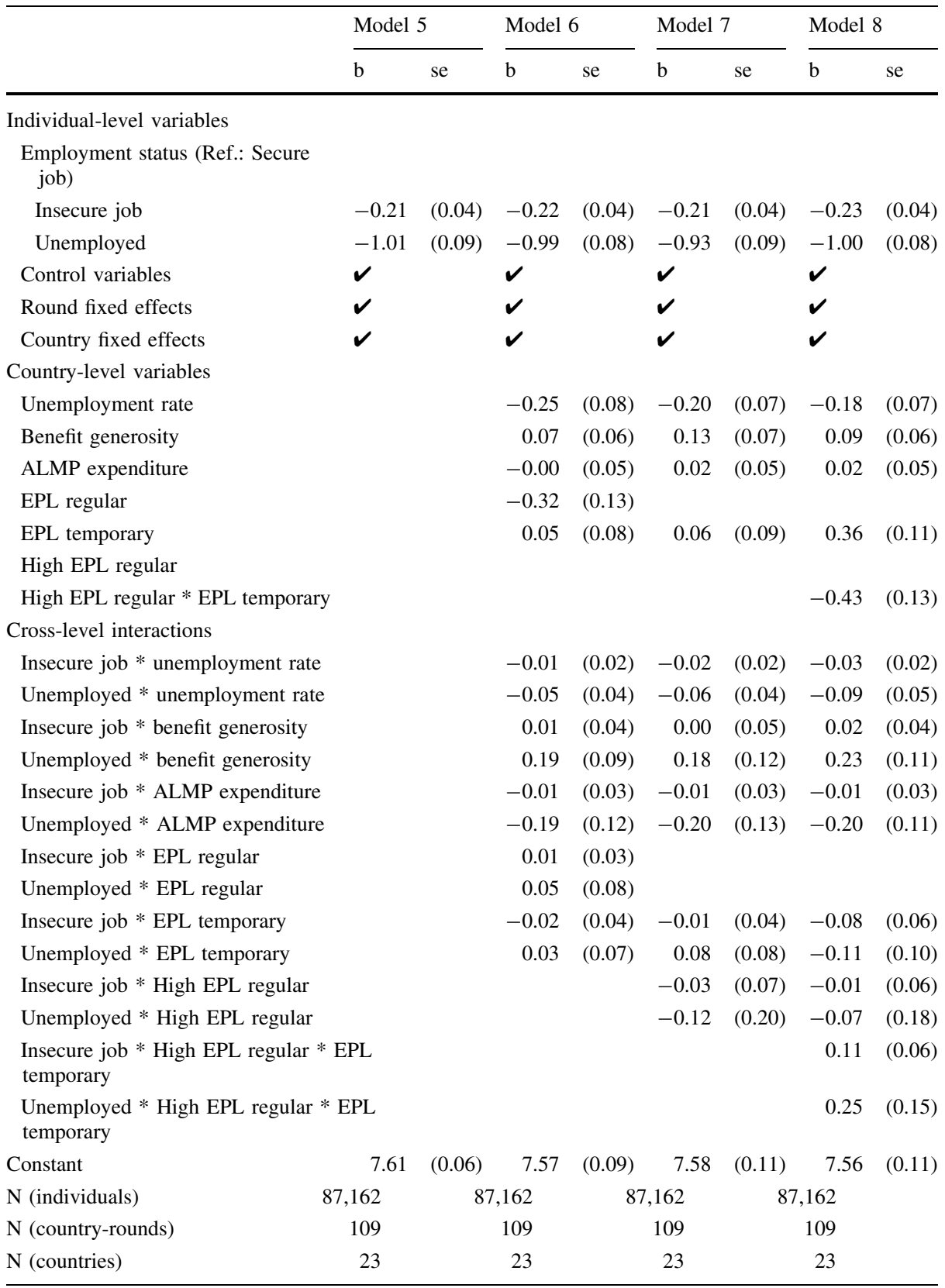

Standard errors clustered by countries; See Table 1 for a list of the individual-level control variables 


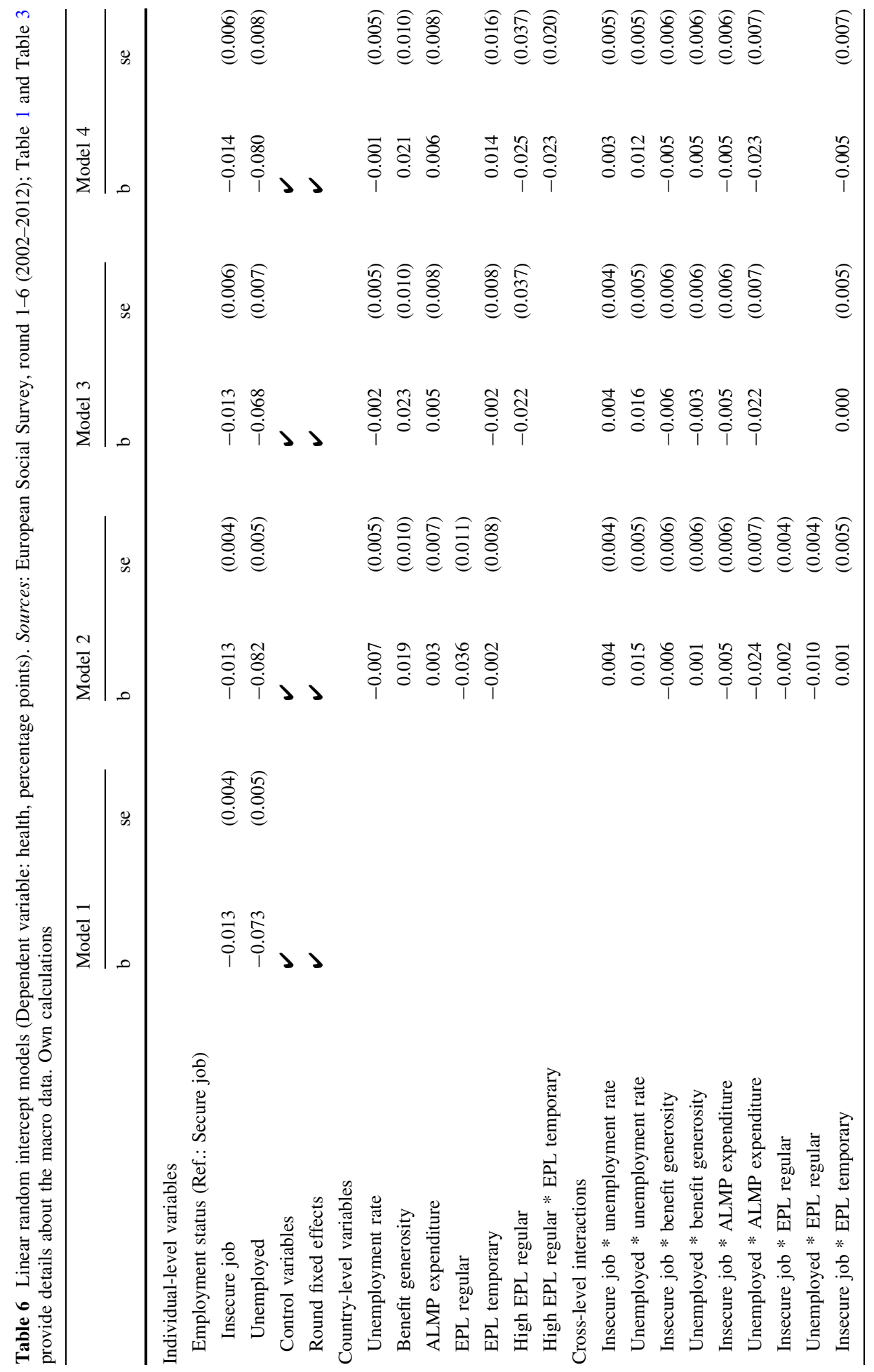




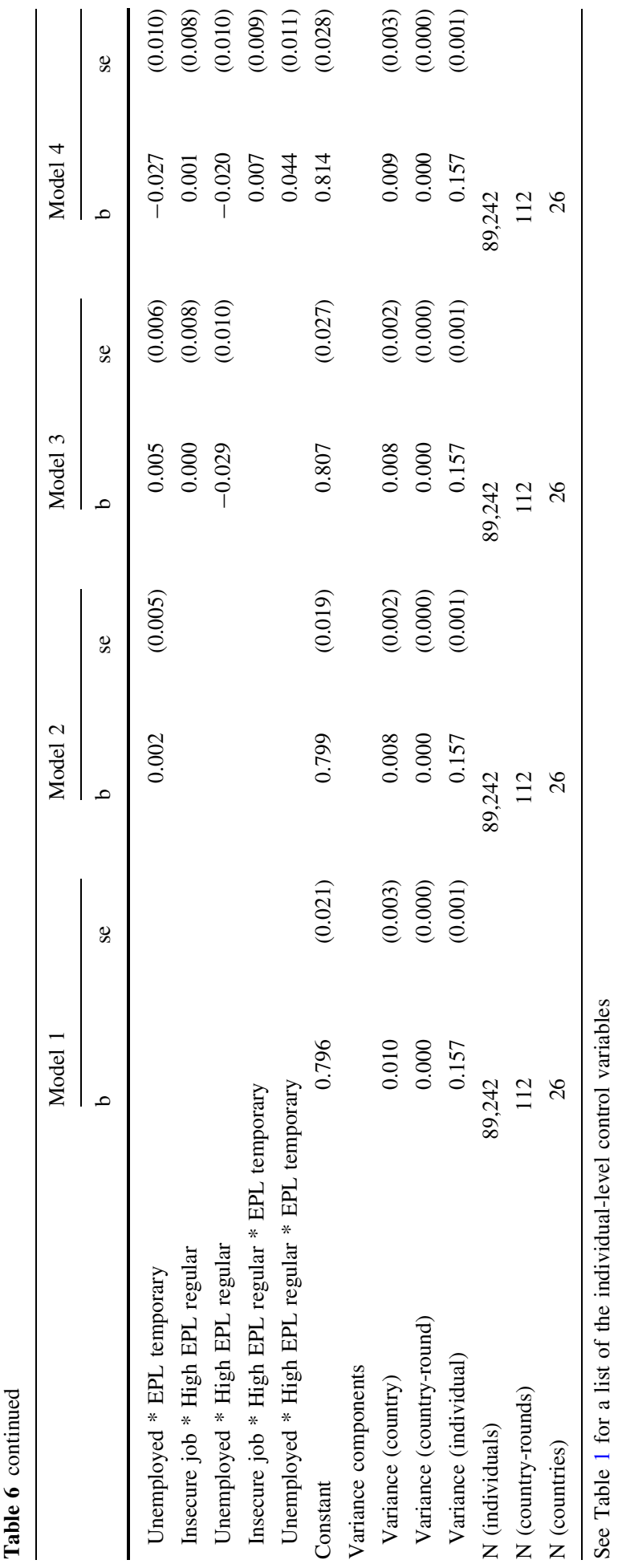




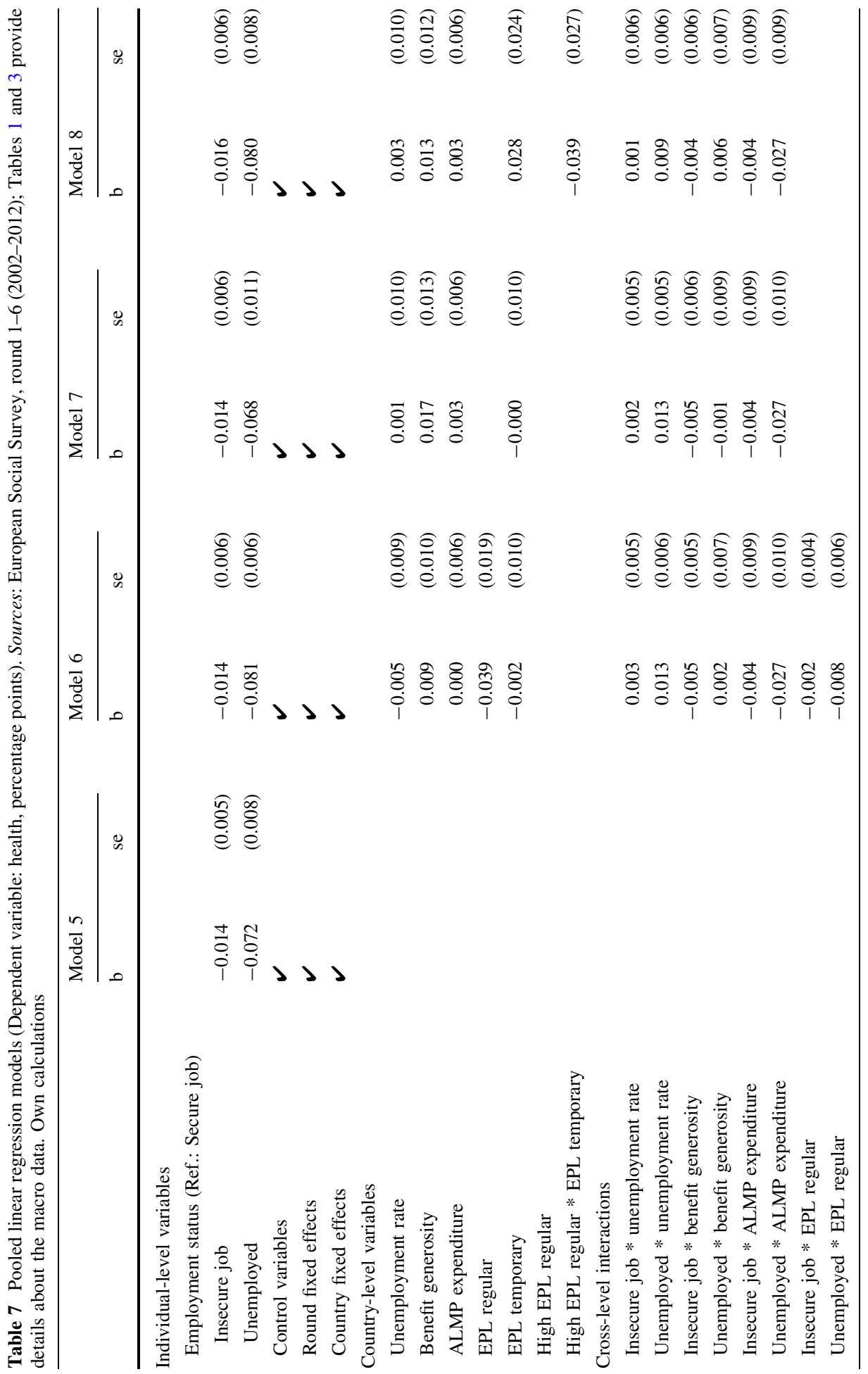




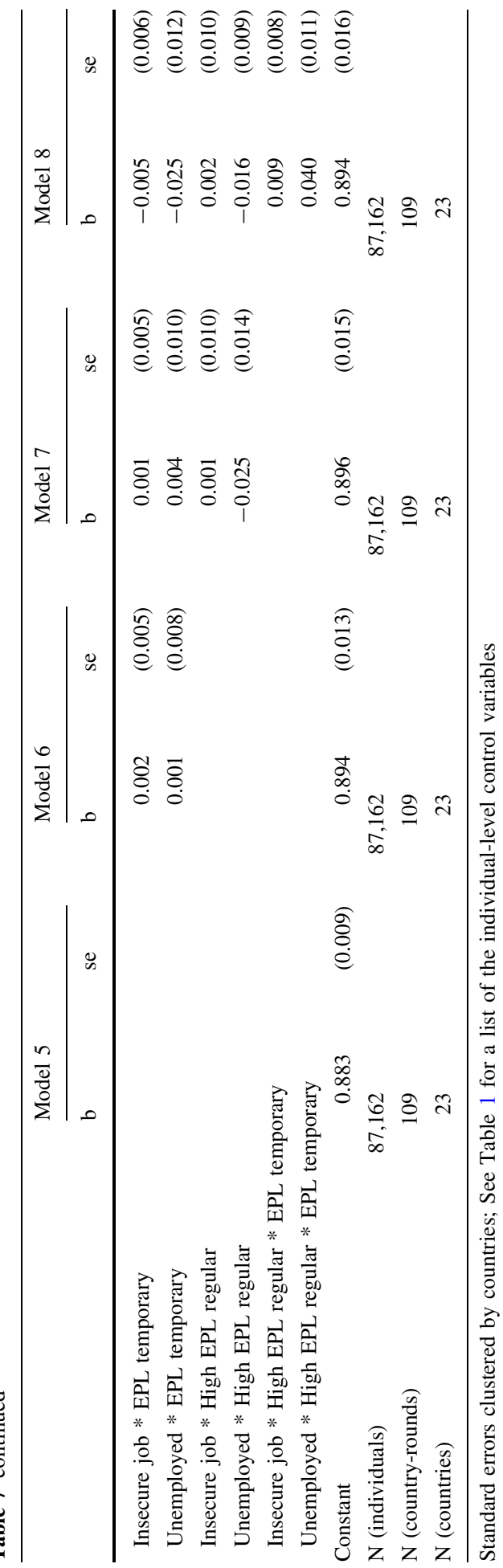




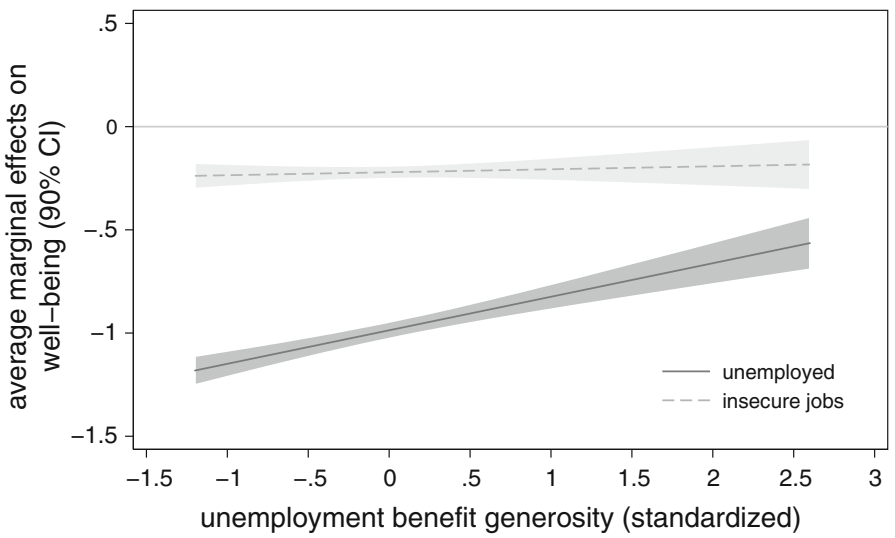

Fig. 1 Average marginal effects of unemployment and insecure jobs on well-being dependent on unemployment benefit generosity. Notes: The standardized unemployment benefit generosity indicator ranges from -1.2 (GB 2008) to 2.6 (BE 2010) in the data. Figure is based on model 2 in Table 4. Sources: European Social Survey, round 1-6 (2002-2012), 26 countries, 112 country-rounds; Tables 1 and 3 provide details about the macro data. Own calculations

expenditure the unemployed are likely composed of individuals who have not been activated and who may be negatively selected in terms of their well-being and health.

With respect to EPL for regular employment (EPLR), we expected that a stricter protection increases the differences between labor market insiders and outsiders (hypothesis 7 and 8), resulting in more negative effects of unemployment and insecure jobs on wellbeing. The results of model 2, using the time-varying EPLR indicator, suggest that the extent of job security provisions does not moderate these effects. The respective interaction coefficients are close to zero and not statistically significant. However, to test our hypotheses about the effects of partial deregulation, we also generated a time-constant indicator distinguishing countries with low EPLR compared to those with high EPLR (High EPL regular in Table 4). ${ }^{8}$ Repeating the analyses for model 2, using the timeconstant EPLR indicator, yields somewhat different results (see model 3). In countries with high EPLR, the negative effect of unemployment on well-being is about -0.16 scale points larger than in countries with low EPLR. For insecure jobs, the results are consistent across model 2 and 3, providing evidence against hypothesis 8. For unemployment, the results, however, depend on the measurement of EPLR, with the time-constant indicator giving an estimate that is in line with hypothesis 7.

Model 4 tests our hypotheses about partial deregulation by including a three-wayinteraction between employment status, the high EPLR indicator, and the time-varying indicator about restrictions on the use of temporary employment (EPLT). Our main interest is in the coefficients for the three-way-interactions reflecting the differences in the moderating effects of EPLT in countries with low and high EPLR.

To facilitate the interpretation of the results, Fig. 2 plots the average marginal effects of unemployment and insecure jobs on well-being against the standardized EPLT indicator. As can be seen from Fig. 2, these effects differ in countries with low and high EPLR.

\footnotetext{
${ }^{8}$ This variable was created by grouping countries by their median sample EPLR. Countries with a median EPLR below/above the overall median are defined, respectively, as low/high EPLR countries.
} 


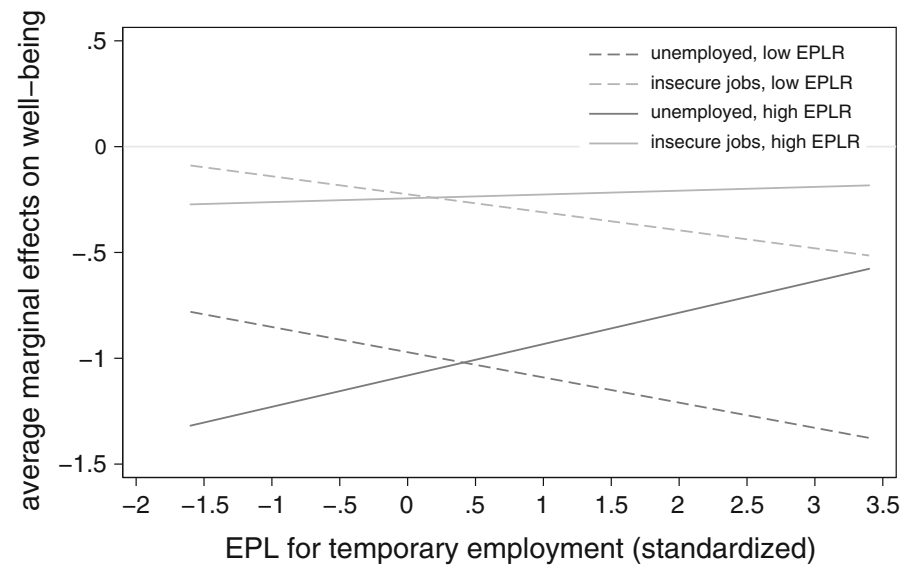

Fig. 2 Average marginal effects of unemployment and insecure jobs on well-being dependent on employment protection legislation for regular and temporary employment. Notes: The standardized EPL for temporary employment indicator ranges from -1.5 (Ireland 2002) to 3.4 (Greece 2002) in the data. Figure is based on model 4 in Table 4. Sources: European Social Survey, round 1-6 (2002-2012), 26 countries, 112 country-rounds; Tables 1 and 3 provide details about the macro data. Own calculations

In line with hypothesis 9, deregulating the restrictions on the use of temporary employment, that is moving in the negative direction on the standardized EPLT indicator, increases the negative effect of unemployment on well-being in countries with high EPLR, but not in those with low EPLR. In the latter, deregulation even has a buffering effect with respect to the negative well-being consequences of unemployment. The difference in the moderating effect of EPLT for countries with low and high protection of insiders is given by the coefficient of the three-way-interaction term in Table 4, model 4 (0.27).

For the effects of insecure jobs the pattern is similar. However, given that in countries with high EPLR the moderating effect of EPLT is almost zero, the finding is only partly in line with hypothesis 10 . The positive interaction coefficient is mostly driven by the fact that in countries with low EPLR deregulating the restrictions on the use of temporary employment buffers the negative effect of insecure jobs on well-being.

Across models 2-4, we also find a negative moderating effect of the unemployment rate on the effect of unemployment, suggesting that individual unemployment has more negative consequences for well-being if aggregate unemployment is high. This result is at odds with the idea that unemployment hurts less if there is more of it around (e.g., Oesch and Lipps 2013).

To test the robustness of these findings, Table 5 reports the results of the analyses using pooled linear regression models including country and round fixed effects (models 5-8). Note that these models are based on 23/109 instead of 26/112 countries/country-rounds, because the three countries that have not been observed repeatedly (see Table 3 ) do not contribute to the estimates of the moderating effects of labor market policies.

Overall, the point estimates are very similar to those reported for the linear random intercept models. Therefore, we only shortly summarize the main findings. Higher unemployment benefit generosity buffers the negative effects of unemployment, but is of little importance with respect to the well-being consequences of insecure jobs. We also find a negative moderating effect for ALMP (model 6). As for the multi-level analyses, the effect of EPL for regular employment (EPLR) depends on the measurement. Only the time- 
constant indicator (model 7) gives a point estimate in line with hypothesis 7, stating that a stricter protection of labor market insiders increases the negative effect of unemployment on well-being. For insecure jobs, the effects are once more small and not statistically significant. ${ }^{9}$

With respect to the partial deregulation hypotheses, the analyses including country fixed effects confirm the findings of the linear random intercept models. For unemployment, we find that deregulating the restrictions on the use of temporary employment (EPLT) increases its negative effects in countries with high EPLR, but alleviates the well-being consequences in countries with low protection for insiders. For insecure jobs, the positive interaction coefficient is rather due to the buffering effect of deregulation in countries with low EPLR.

\subsection{Health}

Table 6 presents the results for the linear random intercept models. The intra class coefficient of the empty model (not shown) indicates that about 6 percent of the variance in health is observed at the country and country-round level. Compared with well-being, this suggests that cross-national differences in self-rated health are smaller than those in life satisfaction, but still practically and statistically significant.

To test hypothesis 1 and 2, model 1 includes the employment status variable as well as the individual-level control variables and round fixed effects. Compared with workers in secure jobs, unemployed individuals, on average, have an about 7.3 percentage point lower probability to be in very good or good health. In contrast, workers in insecure jobs have an only about 1.3 percentage point lower probability of reporting very good or good health. This is in line with hypotheses 1 and 2 as well as confirms the findings for well-being, showing that unemployment is associated with more negative consequences compared with insecure jobs.

Model 2 includes the macro-level variables and the respective cross-level interactions between employment status and labor market policies. In contrast to our findings for wellbeing, the results reveal no positive moderating effect of benefit generosity for the effect of unemployment on health. Hypothesis 3 can, therefore, only be confirmed for life satisfaction. One interpretation may be that unemployment benefits are more conducive to the psychological than the less malleable, physical aspects of health and that well-being is more closely related to the former.

In line with the analyses on well-being, higher expenditures on ALMP increase the negative effect of unemployment on health. A one standard deviation increase in spending per unemployed increases the negative effect on health by about 2.4 percentage points. However, as for well-being this result may be interpreted differently (see above and conclusions section).

Considering EPLR, the results for both the time-varying (model 2) and time-constant indicator (model 3) are in line with hypothesis 7, stating that a stricter protection for labor market insiders is associated with more negative effects of unemployment on health. A one standard deviation increase in EPLR is predicted to increase the negative effect of unemployment on health by about 1 percentage point (model 2) and in countries with a high EPLR the negative effect of unemployed is increased by about 2.9 percentage points (model 3). For the effect of insecure jobs, the EPLR again seems to be of little importance.

\footnotetext{
${ }^{9}$ Note that we cannot estimate a "main effect" for high EPLR. This is due to the fact that the model includes country fixed effects.
} 
For the restrictions concerning the use of temporary employment (EPLT), the moderating effect differs between countries with low and high protection for insiders. Specifically, in high EPLR countries, a standard deviation decrease (deregulation) in EPLT is predicted to increase the negative effect of unemployment on health by about 1.7 percentage points $(=-0.027+0.044)$ while in countries with low protection for insiders the negative effect is expected to be alleviated by about 2.7 percentage points (model 4). In contrast to the findings for well-being, the coefficient of the three-way-interaction term for insecure jobs is, however, not statistically significant. For the control variable, unemployment rate, the results are opposite to the findings concerning well-being meaning that higher aggregate unemployment reduces the negative effect of individual unemployment on being in very good or good health.

Looking at the point estimates of the pooled linear regression models including country and round fixed effects, we find very similar results. Table 7 presents the respective models. Similar to the linear random intercept models, the only practically significant moderating effects are found for unemployment.

Based on within country changes in labor market policies, model 6 suggest no buffering effects of benefit generosity, but a negative moderating effect of expenditures on ALMP. Also for the analyses concerning the EPL for regular employment (EPLR) and the partial deregulation, the results of the linear random intercept models are mostly confirmed.

Before concluding, we briefly report on some additional robustness checks. First, we tested whether our results are affected by influential country-rounds and countries by reestimating a specific model many times and deleting each country-round or country once. ${ }^{10}$ Concerning the analyses excluding each country-round once, we find that our results are quite robust and that the estimates for the cross-level interactions vary only slightly. However, for the analyses excluding each country once (all country-rounds of the respective country are excluded), we find that the positive buffering effect of unemployment benefit generosity depends on the inclusion of Portugal. Similarly, the negative moderating effect of high EPLR depends on Germany being included. ${ }^{11}$ Second, we tested whether the results for benefit generosity are sensitive to measurement. Using the expenditure on PLMP per unemployed as a percentage of GDP growth per capita as an alternative indicator (see Table 1 for definitions), we do not find a positive moderating effect of higher benefit generosity on the effect of unemployment on well-being. Moreover, we find an alleviating effect of higher benefit generosity for the negative effect of insecure jobs on health. The implications of these robustness checks will be discussed in the next section.

\section{Conclusion}

This article complements previous research on the effects of unemployment and insecure jobs on well-being and health as well as the moderating role of labor market policies (e.g., Carr and Chung 2014; Eichhorn 2014; Wulfgramm 2014; Scherer 2009). Specifically, it

\footnotetext{
${ }^{10}$ We used Model 3 from Table 4 for these robustness checks, because many of our substantive conclusions are based on this model.

11 A detailed examination of the data shows that the positive moderating effect of benefit generosity decreases after excluding Portugal, because, on average, Portugal's country-rounds combine a medium to high benefit generosity with small negative effects of unemployment on well-being. Similarly, the negative moderating effect of high EPLR vanishes after excluding all country-rounds of Germany, because they combine a high EPLR with large negative effects of unemployment on well-being.
} 
examines how unemployment and insecure jobs affect life satisfaction and self-rated health and highlights to what extent differences in PLMP, ALMP, and EPL can explain crossnational variation.

Drawing on micro data from round 1-6 of the European Social Survey (2002-2012) and using harmonized information for more than 89,000 individuals, the results reveal that both unemployment and insecure jobs have negative effects on well-being and health. In particular, the effect of unemployment is about five times larger than the effect of having only a temporary contract or no contract at all. This suggests that unemployment still represents the greater threat to workers' well-being and health (e.g., Gebel and Voßemer 2014). Complementing the micro data with time-varying macro indicators, the analyses, however, also show that the negative effects of unemployment and less so insecure jobs vary with welfare states' institutional arrangements.

In line with previous research (see O'Campo et al. 2015 for a review), we find that generous unemployment benefits can buffer the negative effects of unemployment on wellbeing substantially. This result also holds if we only focus on within-country changes in benefit generosity and, thereby, eliminate time-constant unobserved heterogeneity between countries. This is important, because it reduces concerns about the cross-cultural comparability of subjective well-being (Boarini et al. 2013). However, we do not find a positive moderating effect in the analyses concerning self-rated health, suggesting that labor market policies may work better with respect to the psychological than the physical aspects of health.

In contrast to previous studies (e.g., Carr and Chung 2014; Scherer 2009), we also do not find that unemployment benefits are able to mitigate well-being and health inequalities within the workforce, that is, between workers in secure and insecure jobs. This may have several reasons. For example, Carr and Chung (2014) focus on subjective employment insecurity, while we examine differences by contract status. Another reason may be differences in the selection of countries. For instance, Scherer (2009) only focuses on 16 Western European countries. Given these different findings, an advantage of the present article is that it provides comparable estimates for the effects of unemployment and insecure jobs as well as how they are moderated by using the same data and methods.

Moving beyond research that focuses on PLMP, we complement the few previous studies (Carr and Chung 2014; Wulfgramm 2014) that have examined the moderating role of ALMP. We show that ALMP are of little importance for the negative effects of insecure jobs on well-being and health (see Carr and Chung 2014 for a different result). The results, however, also reveal that the negative effects of unemployment on well-being and health increase in countries with higher spending on ALMP. Assuming that ALMP participants are mostly included among the unemployed, this finding, although consistent across different models, is at odds with our theoretical arguments that emphasized the positive aspects of activation in terms of providing a "functional equivalent" to work and the increased employability associated with investments in unemployed individuals' skills.

However, we also discussed that previous research shows that these positive effects are dependent on how closely, for example, job creation measures resemble regular employment or whether the unemployed perceive that the received training really helps them to compete on the labor market. Thus, negative moderating effects of ALMP may also be explained by the fact that ALMP involve forcing elements and may be perceived as paternalistic. An additional, more positive explanation for the negative coefficients of the cross-level interactions may be that higher ALMP expenditure works well resulting in a selective pool of unemployed individuals who have not yet been activated and have lower well-being as well as worse health. Unfortunately, our data do not allow us to disentangle 
these issues higlighting the need for comparative data that include information on participation in active labor market programs. The one previous study which has examined the role of ALMP finds that higher expenditures have either a small buffering effect (model without other cross-level interactions) or no effect at all (model with adding a cross-level interaction for benefit generosity) (Wulfgramm 2014). Thus, more evidence needs to be accumulated, before the moderating role of ALMP on the effects of unemployment on well-being and health can be assessed.

Lastly, we also find that EPL may moderate the negative effects of unemployment on well-being and health. Specifically, we provide empirical evidence for our expectations that the negative effect of unemployment is stronger in countries with a stricter protection of labor market insiders. Distinguishing between job security provisions for workers in regular employment and the restrictions on the use of temporary employment, we also find that deregulating the latter exacerbates the negative effects of unemployment, but only in countries with high EPLR. This result is in line with concerns that a partial deregulation or a flexibilization at the margins may have resulted in a particularly strong cleavage between insiders and outsiders (Barbieri 2009).

Although our results indicate the importance of labor market policies, the following limitations have to be considered. First, similar to other cross-national comparative studies, our micro-level analyses are based on cross-sectional data making a causal interpretation of the effects of unemployment and insecure jobs difficult (e.g., Gebel and Voßemer 2014). Specifically, our estimates may be biased, because of issues of reverse causality and selection on unobserved characteristics. As our focus is on the moderating role of labor market policies, we, however, use panel data and a country fixed effects approach at the macro-level to take account of time-constant unobserved heterogeneity between countries. Second, some of the results are sensitive to measurement as well as the inclusion of specific countries. For example, we do not find a positive moderating effect of unemployment benefit generosity when using an expenditure-based indicator for PLMP. This result highlights that the ambiguous findings of previous studies (e.g., Eichhorn 2014 finds no positive moderating effect; Wulfgramm 2014 finds a positive moderating effect) may, in part, be explained by different measurements. However, we consider the results using the benefit generosity index as more reliable, given that it is clear what aspects of generosity it reflects. Similarly, the negative moderating effect of high EPLR for the effect of unemployment on well-being depends on whether a time-varying or time-constant indicator is used. Moreover, robustness checks suggest that some effects depend on specific countries being included in the analyses pointing to another source for ambiguous findings across different studies. Third, our article highlights the need for better macro indicators. For example, information on the amount of money spent on ALMP confounds the quantitative and qualitative aspects of the underlying measures.

Nevertheless, this study illustrates the role of labor market policies in shaping the experience of both unemployment and insecure jobs. Complementing studies on the moderating role of PLMP, with analyses on ALMP and EPL, therefore, seems to be a valuable avenue for future research. It provides a more comprehensive picture on how welfare states intervene to reduce inequalities in well-being and health. One line of research that allows addressing these issues further would be to examine how different labor market policies combine to alleviate the negative effects of unemployment and insecure jobs on well-being and health.

Acknowledgements The authors thank two anonymous reviewers as well as the discussants and participants of the 3rd EXCEPT Workshop at the University of Bamberg, Germany, 2016 and the 3rd International 
ESS Conference at the University of Lausanne, Switzerland, 2016 for their insightful comments and suggestions.

Funding This project has received funding from the European Union's Horizon 2020 research and innovation programme under Grant Agreement No. 649496.

Open Access This article is distributed under the terms of the Creative Commons Attribution 4.0 International License (http://creativecommons.org/licenses/by/4.0/), which permits unrestricted use, distribution, and reproduction in any medium, provided you give appropriate credit to the original author(s) and the source, provide a link to the Creative Commons license, and indicate if changes were made.

\section{References}

Avdagic, S. (2015). Does deregulation work? Reassessing the unemployment effects of employment protection. British Journal of Industrial Relations, 53, 6-26.

Bambra, C., \& Eikemo, T. A. (2009). Welfare state regimes, unemployment and health: A comparative study of the relationship between unemployment and self-reported health in 23 European countries. Journal of Epidemiology and Community Health, 63, 92-98.

Barbieri, P. (2009). Flexible employment and inequality in Europe. European Sociological Review, 25, 621-628.

Boarini, R., Comola, M., de Keulenaer, F., Manchin, R., \& Smith, C. (2013). Can governments boost people's sense of well-being? The impact of selected labour market and health policies on life satisfaction. Social Indicators Research, 114, 105-120.

Buffel, V., Van de Velde, S., \& Bracke, P. (2015). The mental health consequences of the economic crisis in Europe among the employed, the unemployed, and the non-employed. Social Science Research, 54, 263-288.

Carr, E., \& Chung, H. (2014). Employment insecurity and life satisfaction. The moderating influence of labour market policies across Europe. Journal of European Social Policy, 24, 383-399.

De Cuyper, N., Jong, J. D., De Witte, H., Isaksson, K., Rigotti, T., \& Schalk, R. (2008). Literature review of theory and research on the psychological impact of temporary employment. Towards a conceptual model. International Journal of Management Reviews, 10, 25-51.

De Witte, H. (2005). Job insecurity. Review of the international literature on definitions, prevalence, antecedents and consequences. SA Journal of Industrial Psychology, 31, 1-6.

Diener, E., Inglehart, R., \& Tay, L. (2013). Theory and validity of life satisfaction scales. Social Indicators Research, 112, 497-527.

Eichhorn, J. (2014). The (non-) effect of unemployment benefits. Variations in the effect of unemployment on life-satisfaction between EU countries. Social Indicators Research, 119, 389-404.

European Social Survey. (2016). ESS-6 2012 documentation report. Edition 2.2. Bergen: European Social Survey Data Archive, Norwegian Social Science Data Services for ESS ERIC.

Eurostat. (2013). Labour market policy statistics. Methodology 2013. Luxembourg: Publications Office of the European Union.

Ezzy, D. (1993). Unemployment and mental health. A critical review. Social Science and Medicine, 37, $41-52$.

Ferrer-i-Carbonell, A., \& Frijters, P. (2004). How important is methodology for the estimates of the determinants of happiness? The Economic Journal, 114, 641-659.

Gebel, M., \& Voßemer, J. (2014). The impact of employment transitions on health in Germany. A difference-in-differences propensity score matching approach. Social Science and Medicine, 108, $128-136$.

Gundert, S., \& Hohendanner, C. (2015). Active labour market policies and social integration in Germany: Do 'One-Euro-Jobs' improve individuals' sense of social integration? European Sociological Review, 31, 780-797.

Headey, B., Kelley, J., \& Wearing, A. J. (1993). Dimensions of mental health: Life satisfaction, positive affect, anxiety and depression. Social Indicators Research, 29, 63-82.

Idler, E. L., \& Benyamini, Y. (1997). Self-rated health and mortality: A review of twenty seven community studies. Journal of Health and Social Behavior, 38, 21-37.

Jahoda, M. (1982). Employment and unemployment. A social-psychological analysis. Cambridge, NY: Cambridge University Press. 
Kim, I.-H., Muntaner, C., Vahid Shahidi, F., Vives, A., Vanroelen, C., \& Benach, J. (2012). Welfare states, flexible employment, and health: A critical review. Health Policy, 104, 99-127.

Kohler, U. (2008). Assessing the quality of European surveys. Towards an open method of coordination for survey data. In J. Alber, T. Fahey, \& C. Saraceno (Eds.), Handbook of quality of life in the enlarged European Union (pp. 405-423). London: Routledge.

Korpi, T. (2001). Accumulating disadvantage. Longitudinal analyses of unemployment and physical health in representative samples of the Swedish population. European Sociological Review, 17, 255-273.

Nordenmark, M., \& Strandh, M. (1999). Towards a sociological understanding of mental well-being among the unemployed. The role of economic and psychosocial factors. Sociology, 33, 577-597.

O’Campo, P., Molnar, A., Ng, E., Renahy, E., Mitchell, C., Shankardass, K., et al. (2015). Social welfare matters. A realist review of when, how, and why unemployment insurance impacts poverty and health. Social Science and Medicine, 132, 88-94.

Ochsen, C., \& Welsch, H. (2012). Who benefits from labor market institutions? Evidence from surveys of life satisfaction. Journal of Economic Psychology, 33, 112-124.

OECD. (1997). Is job insecurity on the increase in OECD countries? Chapter 5 in Employment outlook. Paris: OECD.

OECD. (2002). Taking the measure of temporary employment. Chapter 3 in Employment outlook. Paris: OECD.

Oesch, D., \& Lipps, O. (2013). Does unemployment hurt less if there is more of it around? A panel analysis of life satisfaction in Germany and Switzerland. European Sociological Review, 29, 955-967.

Paul, K. I., \& Moser, K. (2009). Unemployment impairs mental health. Meta-analyses. Journal of Vocational Behavior, 74, 264-282.

Scherer, S. (2009). The social consequences of insecure jobs. Social Indicators Research, 93, 527-547.

Schmidt-Catran, A. W., \& Fairbrother, M. (2016). The random effects in multilevel models: Getting them wrong and getting them right. European Sociological Review, 32, 23-38.

Scruggs, L., Jahn, D., \& Kuitto, K. (2014). Comparative welfare entitlements dataset 2. Version 2014-03. University of Connecticut and University of Greifswald.

Sjöberg, O. (2010). Social insurance as a collective resource: Unemployment benefits, job insecurity and subjective well-being in a comparative perspective. Social Forces, 88, 1281-1304.

Strandh, M. (2000). Different exit routes from unemployment and their impact on mental well-being. The role of the economic situation and the predictability of the life course. Work, Employment \& Society, 14, 459-479.

Strandh, M. (2001). State intervention and mental well-being among the unemployed. Journal of Social Policy, 30, 57-80.

Strandh, M., Winefield, A. H., Nilsson, K., \& Hammarström, A. (2014). Unemployment and mental health scarring during the life course. European Journal of Public Health, 24, 440-445.

Sverke, M., Hellgren, J., \& Näswall, K. (2002). No security. A meta-analysis and review of job insecurity and its consequences. Journal of Occupational Health Psychology, 7, 242-264.

Venn, D. (2009). Legislation, collective bargaining and enforcement: Updating the OECD employment protection indicators. OECD Social, Employment, and Migration Working Papers 89. Paris: OECD.

Virtanen, M., Kivimäki, M., Joensuu, M., Virtanen, P., Elovainio, M., \& Vahtera, J. (2005). Temporary employment and health. A review. International Journal of Epidemiology, 34, 610-622.

Wanberg, C. R. (2012). The individual experience of unemployment. Annual Review of Psychology, 63, 369-396.

Wulfgramm, M. (2014). Life satisfaction effects of unemployment in Europe. The moderating influence of labour market policy. Journal of European Social Policy, 24, 258-272. 